\title{
The Effects on the Atmospheric Lunar Tide of the Meridional Temperature Gradient and the Zonal Winds
}

\author{
By Saburo Miyahara \\ Department of Physics, Faculty of Science, Kyushu University \\ (Manuscript received 19 October 1974, in revised form 14 December 1974)
}

\begin{abstract}
The effects on the semidiurnal lunar tide of the meridional temperature gradient and the associated zonal winds are discussed by a linear theory with a numerical method.

It is shown that the zonal wind, its horizontal shear, and its vertical shear affect the latitudinal distributions and the vertical wave length of the oscillation considerably.

For instance, the amplitude becomes larger in westerly winds than in easterly winds, and the vertical wave length is reduced by equator-symmetric easterly winds, but is lengthened by equator-symmetric westerly winds.

It is also shown that the effect of the meridional temperature gradient itself is also considerable, especially in the upper atmosphere.

It is suggested that the seasonal variation of the zonal wind system may be one of the important causes for the statistically observed seasonal variation of the lunar tide.
\end{abstract}

\section{Introdaction}

It has been so far assumed in most tidal theories that the undisturbed atmosphere is at rest relative to the earth and the horizontal temperature gradient does not exist. The meridional temperature gradient and the associated zonal winds, however, are not small in the actual atmosphere, so that the tidal oscillations may be affected considerably by these factors.

Few works have been done about this problem because of mathematical complications. The effect of the meridional temperature gradient alone was studied by Haurwitz (1957) and Siebert (1957), and was shown to be negligibly small. Another effect of the meridional temperature gradient comes from the associated zonal winds. The effect of the zonal winds may be divided into two parts, the one is due to the zonal winds itself and its horizontal shear, while the other is due to the vertical shear. The former effect was studied by Chiu (1953) for an autobarotropic atmosphere, and by Ivanovsky and Semenovsky (1971). The former author's conclusion that the effects on the semidiurnal tide are negligibly small is due to the autobarotropic assumption.

It will be shown in the present paper that the effects of the zonal winds and its horizontal shear are found very large, as noted by Ivanovsky and Semenovsky (1971).

The effects of the vertical shear alone were studied by Sawada (1966) and Kusuda \& Sawada (1974), and their results show that the eigen function and the equivalent depth are affected by this factor considerably. The effects of all these factors together were discussed by Wilkes (1963) and by Stokke (1969). The former author did not notice the importance of the Doppler-effect. The latter author assumed that the vertical velocity was zero at all levels.

Although all these papers employed various different approximations, it is now apparent that the effects of the meridional temperature gradient are very large. Thus, in order to discuss the properties of propagation of the tidal motions more realistically, one should take into account all these factors together, and have to solve the problem without any unrealistic approximations.

Recent paper by Lindzen and Hong (1974), which appeared when the present paper was almost completed, taking into account all these factors together and employing realistic atmospheric models, showed that the main effect of these factors on solar semidiurnal tide is to give rise to 
the generation of the higher modes which are not originally forced, and also showed that the sensitive response of the lunar tide to the vertical temperature profile (Sawada, 1956) is much reduced by the zonal wind and the meridional temperature gradient.

In the present paper, a linearized equation in the most general form (no physical factor is neglected except for the viscosity and the conductivity) for the atmospheric lunar semidiurnal tides with meridional temperature gradients and associated zonal winds is solved numerically to discuss the fundamental effects of the zonal wind, its horizontal shear, its vertical shear, and the meridional temperature gradient itself, using somewhat simple atmospheric models. In contrast with the present paper, Lindzen and Hong (1974) attempt to explain the discrepancies between the observed solar semidiurnal tide and the results of the classical tidal theory by means of the total effects of these factors.

It will be shown that the effect of the zona wind and its horizontal shear are very large and the effect of its vertical shear is also large. The latitudinal distributions of the amplitude and the phase of the oscillation and the vertical wave length of the oscillation are changed by these factors. These results are consistent with the results that the eigen function and the equivalent depth are much sensitive to the zonal wind and its shears (Sawada, 1966, Ivanovsky and Semenovsky, 1971, Kusuda and Sawada, 1974). These latitudinal distributions of amplitude and phase may contain many higher modes as shown by Lindzen and Hong (1974).

It will be also shown that the effect of the meridional temperature gradient alone on the surface oscillation is small in consistent with the results given by Haurwitz (1957) and Siebert (1957), but its effect is not negligibly small in the upper atmosphere.

It will be also suggested from the present results that the seasonal variation of the zonal wind system may be one of the important causes for the observed seasonal variation of the lunar tide.

\section{Perturbation equations}

In what follows, the hydrostatic balance and the ideal gas law are assumed. It is also assumed that the undisturbed atmosphere is homogeneous in the zonal direction and that a zonal wind system in the undisturbed atmosphere is given by

$$
2 \omega \cos \varphi \cdot V+\frac{\cot \varphi}{a} V^{2}=\frac{1}{\rho_{0}} \frac{1}{a} \frac{\partial P}{\partial \varphi} .
$$

Notations used in this paper are shown in Appendix I.

The viscosity and the thermal conductivity may play important roles on tidal oscillations above some one hundred kilometers (Lindzen, 1970). Our main interest, however, is to find the effects of the baroclinicity on the tidal oscillation. Hence, we assume the adiabatic change and the frictionless motion. Under these assumptions, the linearized equation of motion, the equation of continuity, and the first law of thermodynamics for the tidal oscillation excited gravitationally are written as follows;

$$
\begin{aligned}
& \begin{array}{l}
i(\sigma \\
+
\end{array}\left.\frac{s V}{a \sin \varphi}\right) u-\left(2 \omega \cos \varphi+\frac{2 \cot \varphi}{a} V\right) v \\
&=-\frac{1}{a} \frac{\partial}{\partial \varphi}\left(\frac{\partial p}{\rho_{0}}+\Omega\right)-\frac{1}{a} \frac{1}{\rho_{0}^{2}} \frac{\partial \rho_{0}}{\partial \varphi} \partial p \\
&+\frac{1}{a} \frac{1}{\rho_{0}^{2}} \frac{\partial P}{\partial \varphi} \delta \rho \\
& i(\sigma+\left.\frac{s V}{a \sin \varphi}\right) v+\left(2 \omega \cos \varphi+\frac{1}{a} \frac{\partial V}{\partial \varphi}+\frac{\cot \varphi}{a} V\right) u \\
&+w \frac{\partial V}{\partial z}=-\frac{i s}{a \sin \varphi}\left(\frac{\partial p}{\rho_{0}}+\Omega\right) \\
& \frac{\partial}{\partial z}\left(\frac{\partial p}{\rho_{0}}+\Omega\right)+\frac{\delta p}{\rho_{0}^{2}} \frac{\partial \rho_{0}}{\partial z}+\frac{\partial \rho}{\rho_{0}} g=0 \\
& i\left(\sigma+\frac{s V}{a \sin \varphi}\right) \delta \rho+\frac{1}{a} \frac{\partial \rho_{0}}{\partial \varphi} u+w \frac{\partial \rho_{0}}{\partial z}+\rho_{0} \chi=0 \\
& i\left(\sigma+\frac{s V}{a \sin \varphi}\right) \delta p-g \rho_{0} w+\frac{1}{a} \frac{\partial P}{\partial \varphi} u+\gamma P \chi=0
\end{aligned}
$$

where $\chi$ is the divergence defined as

$$
\chi=\frac{1}{a \sin \varphi}\left(\frac{\partial u \sin \varphi}{\partial \varphi}+i S v\right)+\frac{\partial w}{\partial z} .
$$

In equation (2.3), a term, $\frac{V}{a} w$, is neglected in order to be consistent with the hydrostatic assumption.

These equations may by combined into the following single equation for $Q$ which is $\left(\frac{\delta p}{\rho_{0}}+\Omega\right)$, (as to the derivation and the detailed description 
of coefficients, see Appendix II),

$$
\begin{aligned}
A \frac{\partial^{2} Q}{\partial z^{2}} & +B \frac{\partial Q}{\partial z}+C \frac{\partial Q}{\partial \mu}+D \frac{\partial}{\partial \mu}\left[E \frac{\partial Q}{\partial \mu}\right] \\
& +F \frac{\partial}{\partial \mu}[G Q]+I \frac{\partial}{\partial \mu}\left[J \frac{\partial Q}{\partial z}\right]+K \frac{\partial}{\partial z}\left[M \frac{\partial Q}{\partial \mu}\right] \\
& +N \frac{\partial}{\partial z}\left[O \frac{\partial Q}{\partial z}\right]+R \frac{\partial}{\partial z}[S Q]+U Q=W .
\end{aligned}
$$

The wind components are given by

$$
\begin{aligned}
u= & \frac{i \sigma^{\prime}}{4 a \omega^{\prime 2} L}\left[\frac{\partial}{\partial \varphi_{\theta}}+\frac{s}{f^{\prime}} \cot \varphi\right] Q, \\
v= & -\frac{\sigma^{\prime}}{4 a \omega^{\prime 2} L}\left[\left(\frac{\mu}{f^{\prime}}+\frac{1}{a \sigma^{\prime}} \frac{\partial V}{\partial \varphi_{\theta}}-\frac{\cot \varphi}{a \sigma^{\prime}} V\right) \frac{\partial}{\partial \varphi_{\theta}}+\frac{s}{\sin \varphi}\right] Q \\
& -\frac{1}{g} \frac{\partial V}{\partial z}\left[1-\frac{H}{\kappa+\frac{\partial H}{\partial z}} \frac{\partial}{\partial z}\right] Q+\frac{1}{g} \frac{\partial V}{\partial z} \Omega,(2.10) \\
w= & \frac{i \sigma^{\prime}}{g}\left[1-\frac{H}{\kappa+\frac{\partial H}{\partial z}} \frac{\partial}{\partial z}\right] Q+\tan \varepsilon \cdot u-\frac{i \sigma^{\prime}}{g} \Omega,
\end{aligned}
$$

where

$$
\begin{aligned}
& L=f^{\prime 2}-\mu^{2}-\frac{\mu}{2 a \omega^{\prime}} \frac{\partial V}{\partial \varphi_{\theta}}+\frac{\mu}{2 a \omega^{\prime}} \cot \varphi \cdot V, \\
& \frac{\partial}{\partial \varphi_{\theta}}=\frac{\partial}{\partial \varphi}+a \tan \varepsilon \cdot \frac{\partial}{\partial z} \\
& \tan \varepsilon=-\frac{H}{g} \cdot \\
& \frac{\left(2 \omega \mu+\frac{\cot \varphi}{a} V\right)\left\{\frac{\partial V}{\partial z}-\frac{V}{H}\left(\kappa+\frac{\partial H}{\partial z}\right)\right\}+\frac{\cot \varphi}{a} V \frac{\partial V}{\partial z}}{\kappa+\frac{\partial H}{\partial z}}
\end{aligned}
$$

The suffix $\theta$ means that the differentiation is conducted along an isentropic surface, $\theta=$ const., while $\varepsilon$ is the inclination of the isentropic surface (see Appendix II).

Equation (2.8) is dinear, but is complete in a sense that no physical factor is neglected except for the viscosity and the conductivity. If the meridional temperature gradient and the associated zonal winds do not exist, equation (2.8) naturally reduces to the same equation as that of conventional tidal theories. It is seen from equation (2.8) that a part of the effects of the meridional temperature gradient comes from the associated zonal winds and its shears. The meridional temperature gradient itself does not appear explicitly, although its effects are included in each coefficient which depends on $\varphi$.

\section{Results of numerical calculations and discussions}

It has been found that the equivalent depth and the eigen function are affected considerably by zonal winds and its shears (Sawada, 1966, Ivanovsky and Semenovsky, 1971, Kusuda and Sawada, 1974).

In what follows, the semidiurnal lunar tide in a baroclinic atmosphere is discussed by solving equation (2.8) by making use of a numerical method developed by Lindzen and Kuo (1969).

No critical level where $\sigma^{\prime}$ (which is the Dopplershifted frequency) becomes zero exists in this case, because of the large phase velocity of the oscillation. But a singular level where $L$ (see equation (2.12)) becomes zero exists at a high latitude, If we neglect the horizontal wind shear and the curvature of the earth, the singular level reduces to what was indicated by Jones (1967). In order to avoid this singularity, the so-called Rayleigh damping is usually assumed. In the present study, a grid point system is employed, such that there is no grid point on the pole side of the singularity, except for the pole itself, so that the damping assumption need not be used,

The latitudinal finite difference, $\Delta \mu$, is taken as $2 / 17$. In the vertical direction, $\Delta z$ is taken as $2.5 \mathrm{~km}$. The lower boundary condition is that the earth's surface is horizontal and rigid, so that

$$
w=0 \quad \text { at } \quad z=0 .
$$

The atmosphere above one hundred kilometers is assumed to be isothermal with no zonal wind, in order that a radiation condition is used as the upper boundary condition. At the pole, it is assumed that

$$
Q=0 \text { for all } z \text {. }
$$

In order to see the accuracy of the present grid point system, the semidiurnal lunar tide in an isothermal atmosphere with $T=288 \mathrm{~K}$ is calculated and compared with the analytical solutions.

Fig. 1 shows the results of the numerical solution together with analytical one. The both results for the earth's surface seem to agree well with each other. However, the phase of the analytical solution is a little larger than that of numerical one at all levels except for the earth's surface. 


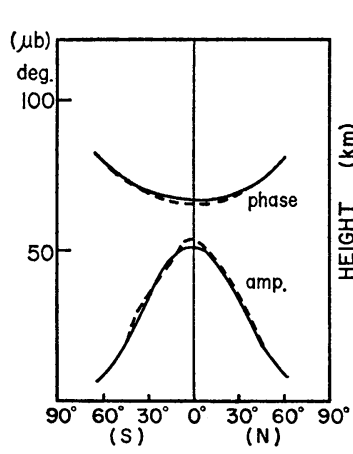

(a)

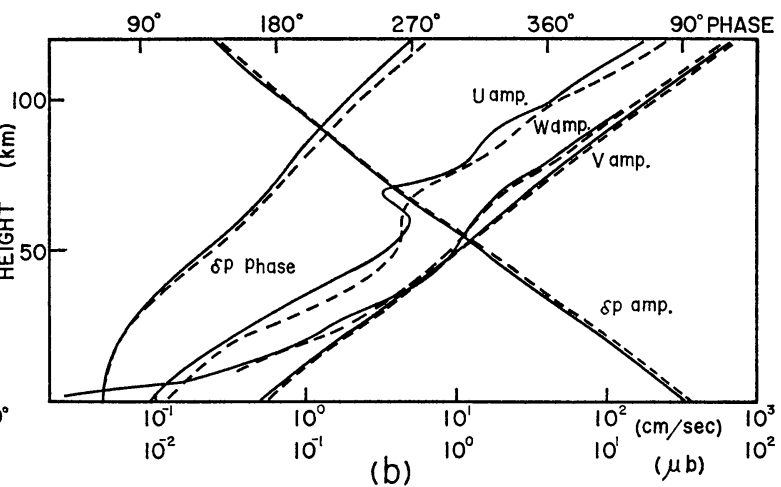

(b)

Fig. 1. (a): The latitudinal distribution of the surface pressure oscillation.

(b): The height distributions of $\delta p, u, v$ and $w$ at $4^{\circ} \mathrm{N}$ in the isothermal atmosphere with $T=288 \mathrm{~K}$.

Solid line: numerical results. Dashed line: analytical results.

This means that the numerically calculated vertical wavelength is a little longer than that of analytical one. This difference shows the order of magnitude of the error in the present grid point system. One should notice, however, that this difference is not random, and that, as far as $\delta p$ is concerned, the difference is in the same sense. This is due to that the numerically calculated equivalent depths apt to be greater than the analitically expected values. Unless the undisturbed state of the atmosphere deviates greatly from an isothermal state, this grid point system may enable us to examine the fundamental effects of the meridional temperature gradient and associated zonal winds on the semidiurnal tide. This will be confirmed when it is shown later that the results of computations are consistent with that found by Ivanovsky and Semenovsky (1971) and Kusuda and Sawada (1974), qualitatively.

In the present paper, several idealized atmospheric models are used, and each of them is named after the distribution of zonal wind in it. For example, "E-W" model has an easterly wind in the southern hemisphere and a westerly wind in the northern hemisphere, and similar terms "W-W" model and "E-E" model are used in a sense that both $\mathrm{E}$ and $\mathrm{W}$ indicate the wind directions of zonal wind system.

In each model, we assume that the mean temperature is $284 \mathrm{~K}$, the undisturbed surface pressure is $1000 \mathrm{mb}$, and the axes of zonal wind with a speed of $50 \mathrm{~m} / \mathrm{sec}$ exist at $30^{\circ} \mathrm{N}$ and $30^{\circ} \mathrm{S}$ at the height of $60 \mathrm{~km}$ (see Fig. 2). With these zonal wind systems, the temperature must deviate from the mean to balance with the winds under equation (2.1).

Except for the necessary deviation due to the zonal wind, the vertical temperature profile is not assumed. This is because we rather planned simply to avoid any effect of the profile itself.

Fig. 2 shows a cross-section of the E-W model with isotachs and isotherms as an example.

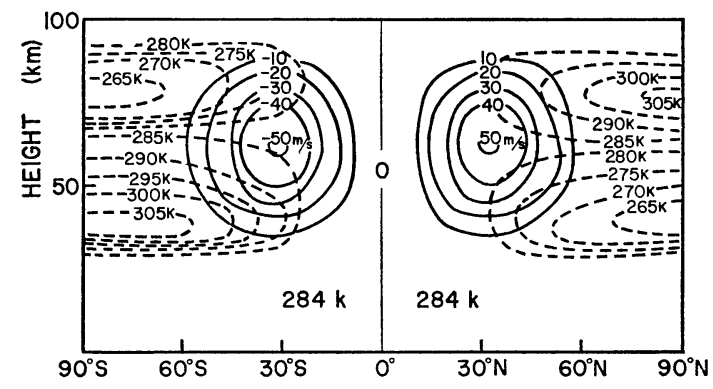

Fig. 2. Meridional cross section of E-W model atmosphere.

Solid lines: isotachs of the zonal wind. Dashed lines: isotherms of the basic temperature.

Fig. 3. through Fig. 5 show the results for the semidiurnal lunar tidal oscillation in E-W model. The pressure oscillations: $\frac{\partial p}{\rho_{0}}$ at the surface and those at the heights of $60 \mathrm{~km}$ and $120 \mathrm{~km}$ are shown in Fig. 3 which is a harmonic dial normalized with the amplitudes at $3^{\circ} \mathrm{S}$ as an unit at each level. This figure shows that the pressure oscillation is asymmetric with respect to the equator in spite of the symmetric tide generating force. This must be due to the asymmetric 


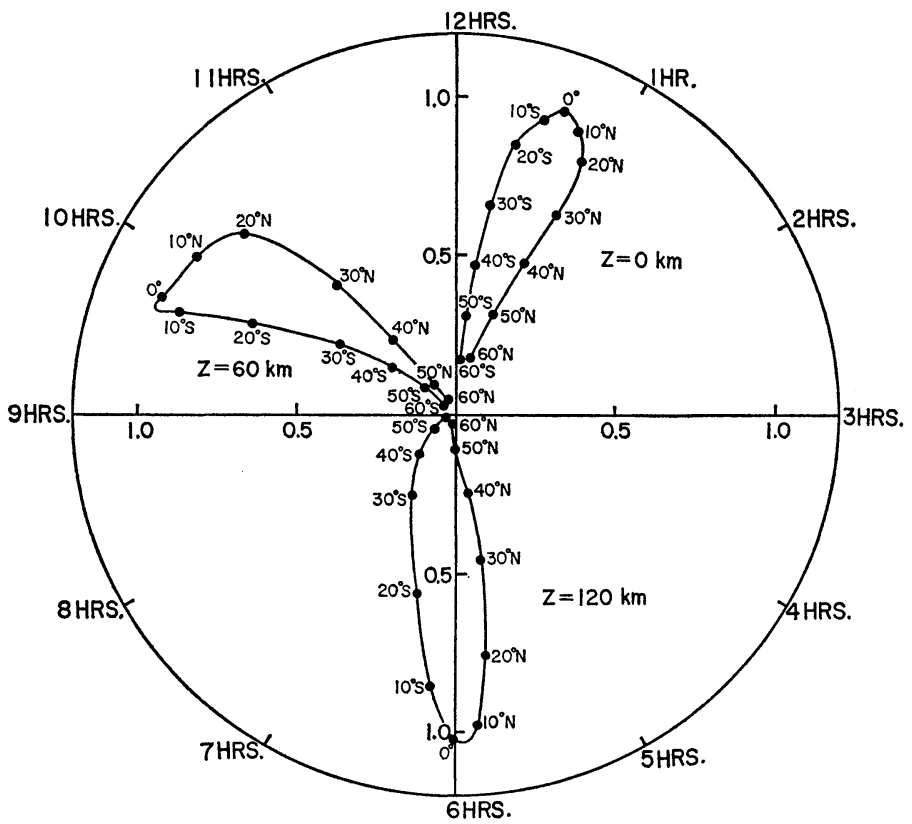

Fig. 3. Harmonic dial for the pressure oscillations: $\frac{\delta p}{\rho_{0}}$ at the heights of $0 \mathrm{~km}, 60 \mathrm{~km}$ and $120 \mathrm{~km}$ in E-W model. The amplitudes are normalized with the amplitudes at $3^{\circ} \mathrm{S}$ as an unit at each level. The amplitude at $3^{\circ} \mathrm{S}$ is $4.19 \times 10^{4}$ $\mathrm{cm}^{2} / \mathrm{sec}^{2}$ at $0 \mathrm{~km}, 7.69 \times 10^{5} \mathrm{~cm}^{2} / \mathrm{sec}^{2}$ at $60 \mathrm{~km}, 2.98 \times 10^{7}$ $\mathrm{cm}^{2} / \mathrm{sec}^{2}$ at $120 \mathrm{~km}$.

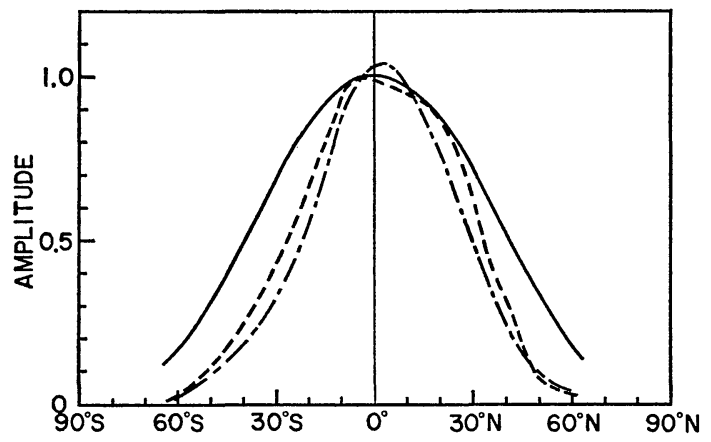

Fig. 4. Latitudinal distributions of the pressure oscillation: $\frac{\delta p}{\rho_{0}}$ in $\mathrm{E}-\mathrm{W}$ model at the heights of $0 \mathrm{~km}, 60 \mathrm{~km}$ and $120 \mathrm{~km}$. The unit is same as Fig. 3.

Solid line: $0 \mathrm{~km}$. Dashed line: $60 \mathrm{~km}$. Dot-dash line: $120 \mathrm{~km}$.

structure of the atmospheric model. The phase lag of the surface pressure oscillation in the northern hemisphere, where is a westerly wind system in the upper atmosphere, is larger than that in the southern hemisphere where is an easterly wind system in the upper atmosphere.

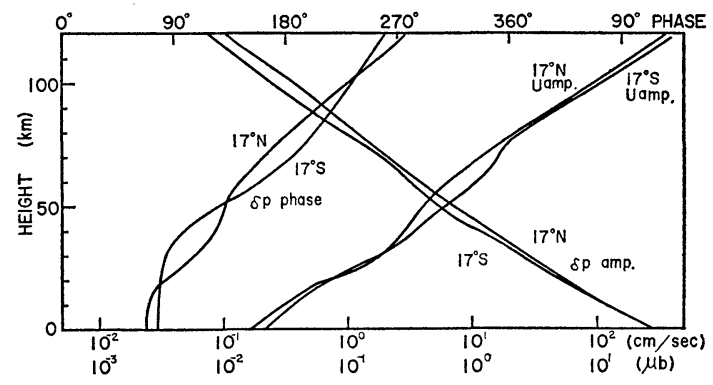

Fig. 5. Height distributions of $\delta p$ and $u$ at $17^{\circ} \mathrm{N}$ and $\mathrm{S}$.

The phase difference between northern and southern hemisphere at the middle latitudinal zone is about thirty minutes. A similar asymmetry with respect to the equator of the surface pressure oscillations is observed statistically in the so-called D season (Haurwitz and Cowly, 1970, Miyahara, 1972), in which zonal wind is westerly in the northern hemisphere, while it is easterly in the southern hemisphere. It is also seen that the oscillation at the height of $60 \mathrm{~km}$, where is a maximum zonal wind speed, shows an asymmetry, 
and that at the height of $120 \mathrm{~km}$, where the atmospheric structure is assumed to be symmetric with respect to the equator, there still exists a similar asymmetry.

Fig. 4 shows the latitudinal distribution of the amplitude of the pressure oscillations: $\frac{\partial p}{\rho_{0}}$. It is apparent from Fig. 4 (also from Fig. 3) that the amplitude in the northern hemisphere is larger than that in the southern hemisphere. This is consistent with a result that the eigen function is larger in a hemisphere where a westerly wind system exists than in other hemisphere where an easterly wind system exists (Ivanovsky and Semenovsky, 1971).

Fig. 5 shows the height distributions of the pressure oscillation, and also those of $u$ at both $17^{\circ} \mathrm{N}$ and $17^{\circ} \mathrm{S}$ where the largest asymmetry is seen. It is again seen from this figure that the amplitude of the pressure oscillation is larger in the northern hemisphere than in the southern hemisphere. At the height of $120 \mathrm{~km}$, where the atmospheric structure is assumed to be symmetric, the oscillation still remains to be asymmetric in a sense that the amplitude is larger in the northern hemisphere owing to the effects of the lower asymmetric atmospheric structure. The phase difference of the pressure oscillations between the northern and the southern hemispheres is not monotonous, but changes its sign almost periodically in the vertical direction. This result indicates that the locally defined vertical wave length is different in each hemisphere. This is due to the different structure of the undisturbed atmosphere in each hemisphere. The amplitude of $u$ is larger in southern hemisphere than in northern hemisphere. This is due to the result that the maximum of the pressure oscillation is shifted to northern hemisphere.

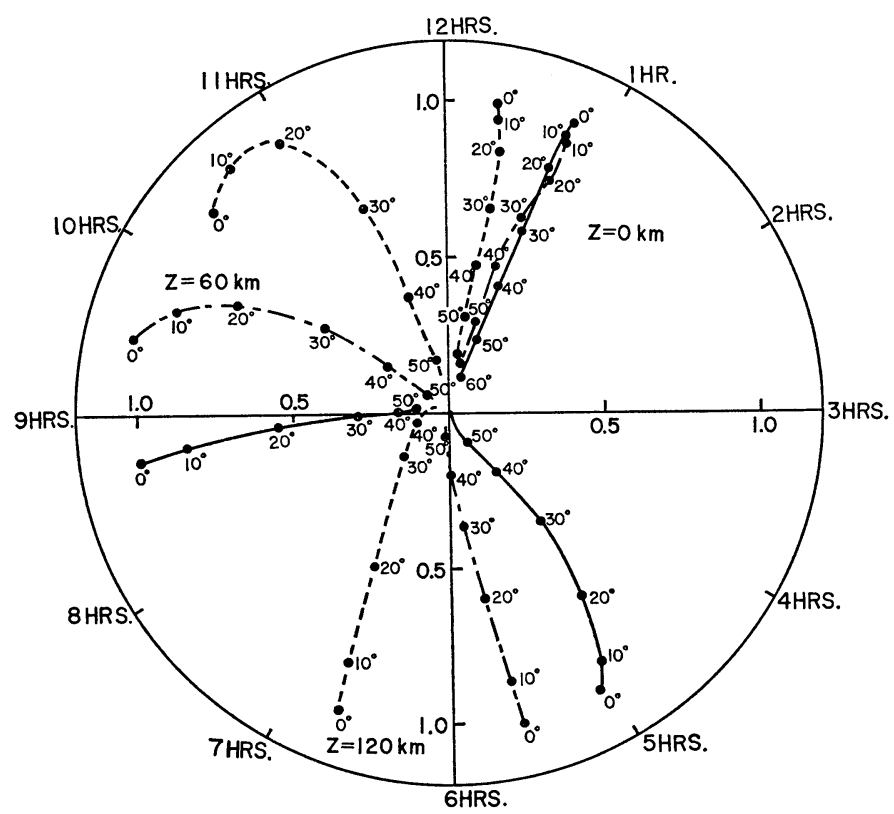

Fig. 6. Harmonic dial for the pressure oscillations: $\frac{\delta p}{\rho_{0}}$ at the heights of $0 \mathrm{~km}, 60 \mathrm{~km}$ and $120 \mathrm{~km}$ in W-W model, E-E model and isothermal model with $T=288 \mathrm{~K}$. The unit is similar to Fig. 3. The amplitude at $3^{\circ} \mathrm{S}$ at each level in each model are shown below.

$\mathrm{W}-\mathrm{W}$ model E-E model isothermal model

$\begin{array}{rlll}0 \mathrm{~km} & 3.96 \times 10^{4} & 5.41 \times 10^{4} & 4.42 \times 10^{4} \\ 60 \mathrm{~km} & 5.18 \times 10^{5} & 1.05 \times 10^{6} & 8.23 \times 10^{5}\left(\mathrm{~cm}^{2} / \mathrm{sec}^{2}\right) \\ 120 \mathrm{~km} & 2.36 \times 10^{7} & 3.62 \times 10^{7} & 3.12 \times 10^{7}\end{array}$

Solid line: E-E model. Dashed line: W-W model. Dotdash line: Isothermal model. 
The above mentioned asymmetric latitudinal distributions of amplitude and phase may contain many higher modes as shown by Lindzen and Hong (1974).

The pressure oscillations: $\frac{\delta p}{\rho_{0}}$ in the $\mathrm{W}-\mathrm{W}$ model and the E-E model atmospheres are shown in Fig. 6 together with that in an isothermal atmosphere with $T=288 \mathrm{~K}$. This figure shows that the vertical wave-length of the oscillation in the E-E model is shorter than that in the isothermal atmosphere, and that in the W-W model, it is longer than that in the isothemal atmosphere. Comparing Fig. 6 with Fig. 3, one finds that the vertical wave length in the E-W model is almost the same with that in the isothermal model. This is found also by comparing Fig. 5 with Fig. 1. These results are consistent with the results that the equivalent depth is amplified by an equatorsymmetric westerly wind system, but is reduced by an equator symmetric easterly wind system, while it is changed only a little by an equatorantisymmetric wind system (Ivanovsky and Semenovsky, 1971).

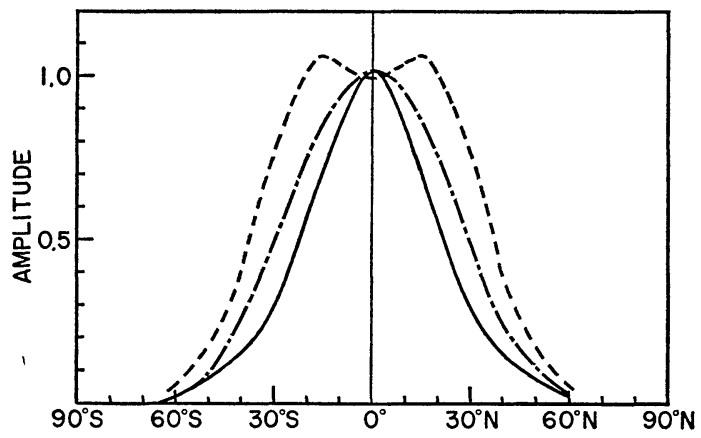

Fig. 7. Latitudinal distributions of the pressure oscillation: $\frac{\delta p}{\rho_{0}}$ at the height of $60 \mathrm{~km}$ in W-W model, E-E model and isothermal model. The unit is same as Fig. 6.

Solid line: E-E model. Dashed line: W-W model. Dot-dash line: isothermal model.

Fig. 7 gives the latitudinal distributions of the amplitude of the pressure oscillation: $\frac{\delta p}{\rho_{0}}$ at the height of $60 \mathrm{~km}$ in these two model atmospheres together with that in the isothermal atmosphere.

In case of the W-W model, the amplitude shows two maxima at around $20^{\circ} \mathrm{N}$ and S. Throughout whole middle latitudinal zones, where exist a westerly wind system, the amplitude is much larger than that in the isothermal atmosphere. On the other hand in case of the E-E model, the amplitude decreases from the equator more rapidly with latitude than that in the isothermal atmosphere. These results altogether show that the semidiurnal tide tends to have larger amplitudes in a westerly wind region than in an easterly wind region.

In order to see which factor of the atmospheric structures gives rise to such effects, calculations are conducted stepwise for the E-W model as follows:

Step I: zonal winds and its shears are dropped from the E-W model while the temperature term is kept,

Step II: zonal winds and its horizontal shear are dropped from the E-W model while its vertical shear and the temperature terms are kept.

The results of computation for each step are shown in Fig. 8 and Fig. 9 respectively. In case of step I, the asymmetries of the amplitude and the phase distributions at the surface are much smaller than those of the case when the no terms are dropped, namely the E-W model itself (see Fig. 3) and also those of the case of step II.

This result shows that the meridional temperature gradient alone in the upper atmosphere is less important than the zonal wind and its shears for the surface oscillations. This is consistent with those obtained by Haurwitz (1957) and Siebert (1957). The differences in amplitude and phase distributions with latitude if compared Fig. 3 with Figs. 8 and 9 is most remarkable at the height of $60 \mathrm{~km}$.

The asymmetry observed in E-W model (Fig. 3) is reduced very much in Figs. 8 and 9. When we consider that the zonal wind system has the maximum wind and the maximum horizontal shear at the height of $60 \mathrm{~km}$, it is apparent that the above mentioned large difference is caused by the zonal wind and its horizontal shear, and this result is consistent with that found by Ivanovsky and Semenovsky (1971). The differences between Fig. 3 and Figs. 8 and 9 at the height of $120 \mathrm{~km}$ where the undisturbed atmospheric structure is assumed symmetric, is also remarkable. This result shows that the zonal wind and the horizontal shear in lower atmospheric layers have larger effects on the oscillation of upper atmosperic layers than that of the vertical shear and the meridional temperature gradient. This may be caused by 


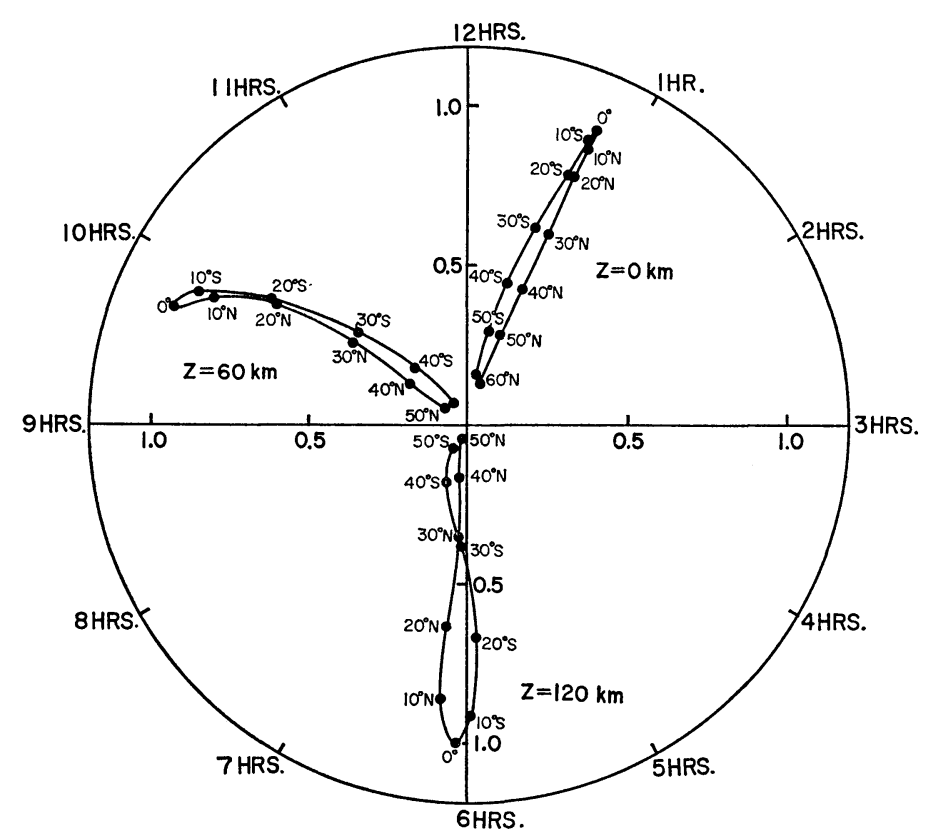

Fig. 8. Harmonic dial for the pressure oscillations: $\frac{\delta p}{\rho_{0}}$ at the heights of $0 \mathrm{~km}, 60 \mathrm{~km}$ and $120 \mathrm{~km}$ in case of step I (see text). The unit is similar to Fig. 3. The amplitude at $3^{\circ} \mathrm{S}$ is $4.29 \times 10^{4} \mathrm{~cm}^{2} / \mathrm{sec}^{2}$ at $0 \mathrm{~km}, 8.77 \times 10^{5} \mathrm{~cm}^{2} / \mathrm{sec}^{2}$ at $60 \mathrm{~km}$ and $3.37 \times 10^{7} \mathrm{~cm}^{2} / \mathrm{sec}^{2}$ at $120 \mathrm{~km}$.

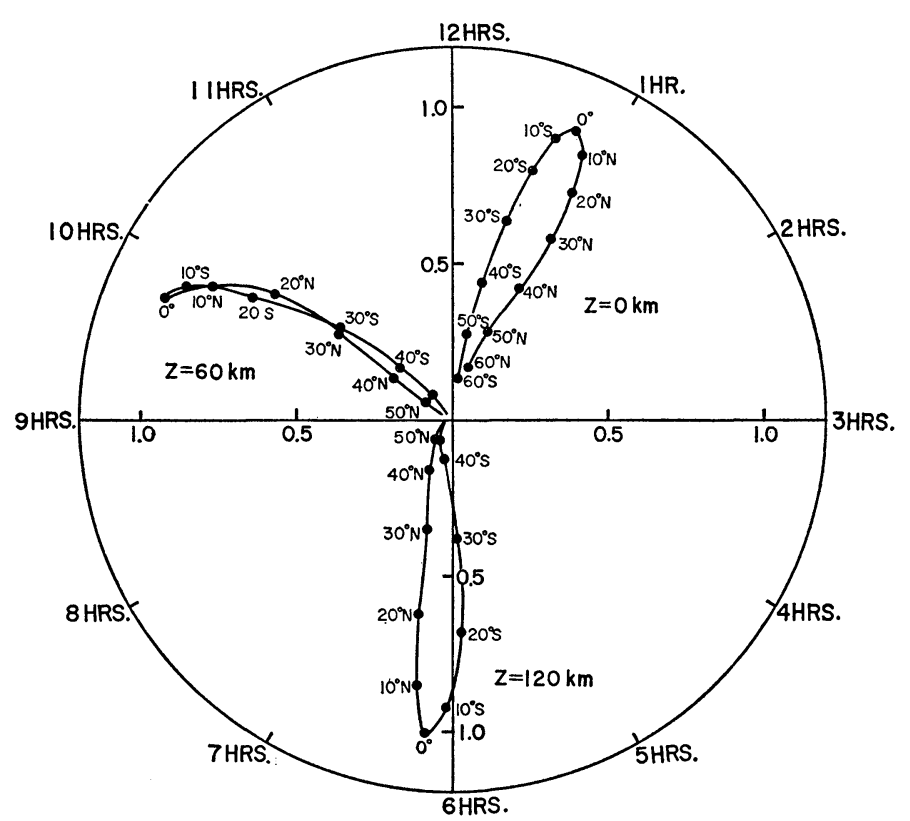

Fig. 9. Harmonic dial for the pressure oscillations; $\frac{\delta p}{\rho_{0}}$ at the heights of $0 \mathrm{~km}, 60 \mathrm{~km}$ and $120 \mathrm{~km}$ in case of step II (see text). The unit is similar to Fig. 3. The amplitude at $3^{\circ} \mathrm{S}$ is $4.27 \times 10^{4} \mathrm{~cm}^{2} / \mathrm{sec}^{2}$ at $0 \mathrm{~km}, 8.96 \times 10^{5} \mathrm{~cm}^{2} / \mathrm{sec}^{2}$ at $60 \mathrm{~km}$ and $3.39 \times 10^{7} \mathrm{~cm}^{2} / \mathrm{sec}^{2}$ at $120 \mathrm{~km}$. 


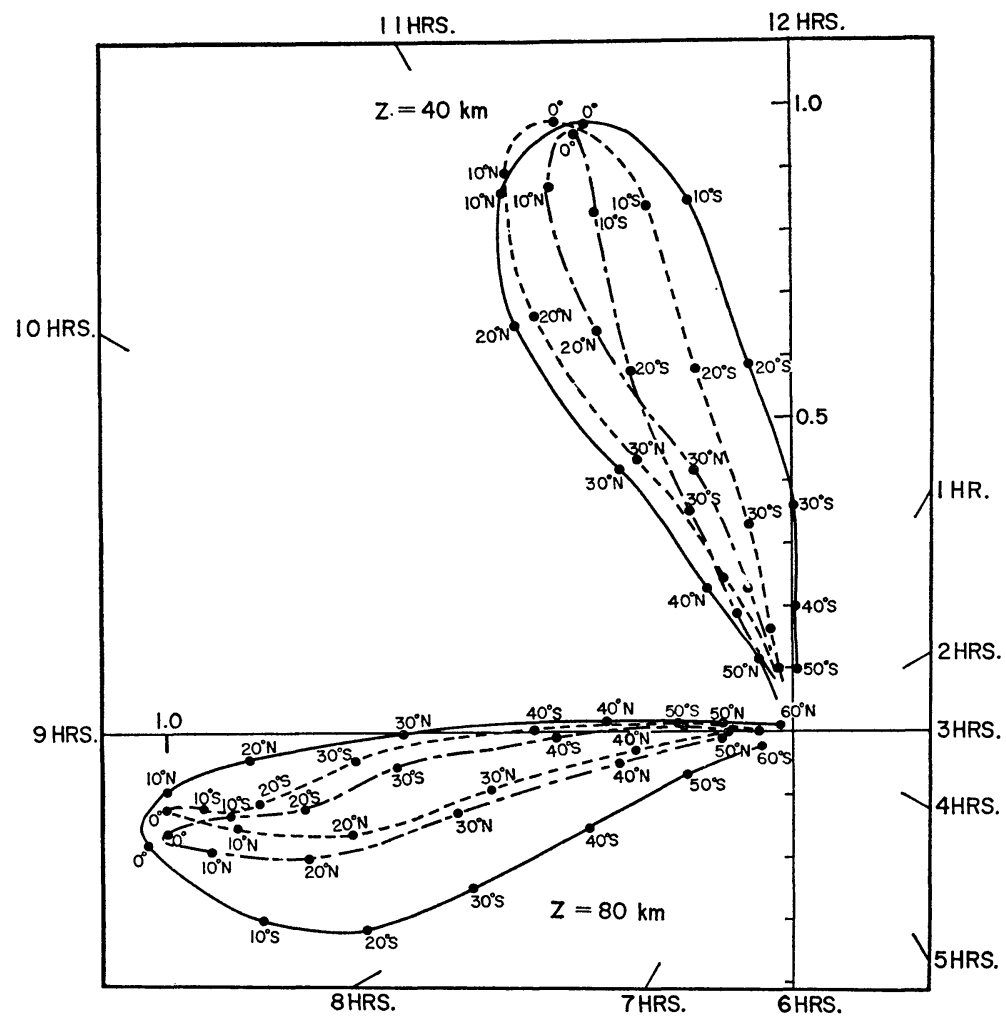

Fig. 10. Harmonic dial for the pressure oscillations; $\frac{\delta p}{\rho_{0}}$ at the heights of $40 \mathrm{~km}$ and $80 \mathrm{~km}$ in case of steps I and II, and E-W model. The unit is similar to Fig. 3. The amplitude at $3^{\circ} \mathrm{S}$ at each level in each case are shown below.

$\begin{array}{cccc} & \text { Step I } & \text { Step II } & \text { E-W model } \\ 40 \mathrm{~km} & 2.83 \times 10^{5} & 2.82 \times 10^{5} & 2.75 \times 10^{5}\left(\mathrm{~cm}^{2} / \mathrm{sec}^{2}\right) \\ 80 \mathrm{~km} & 2.73 \times 10^{6} & 2.75 \times 10^{6} & 2.44 \times 10^{6}\end{array}$

Solid line: E-W model. Dashed line: step II. Dot-dash line: step I.

the assumption that the zonal wind and its horizontal shear have the same sense throughout in the lower atmosphere, while the vertical shear and the meridional temperature gradient change their sense at the height of $60 \mathrm{~km}$ in the present model.

Fig. 3, Figs. 8 and 9 show also that the vertical wave length is changed little by the vertical shear. This is consistent with the result that the equivalent depth is not sensitive to the equatorantisymmetric vertical shear (Kusuda and Sawada, 1974).

Fig. 10 shows the pressure oscillations: $\frac{\delta p}{\rho_{0}}$ in E-W model together with that for steps I and II at the heights of $40 \mathrm{~km}$ and $80 \mathrm{~km}$, where the vertical shear and the meridional temperature gradient become maximum. In case of step I, the amplitude is larger in the northern hemisphere than in the southern hemisphere at the height of $40 \mathrm{~km}$ and vice versa at the height of $80 \mathrm{~km}$. This means that the effect of the meridional temperature gradient alone is not negligibly small in the upper atmosphere. In case of step II, the amplitude is enlarged in a positive shear zone, but is reduced in a negative shear zone. This is consistent with the result that the eigen function has the larger amplitude in a positive shear zone than in a negative shear zone when an equatorantisymmetric shear exists (Kusuda and Sawada, 1974). This figure shows, however, that the 

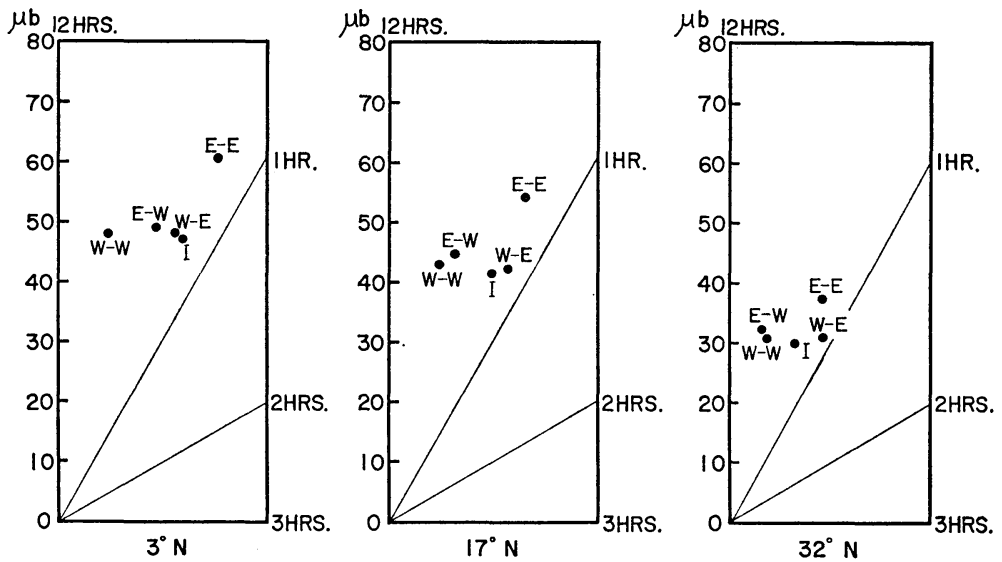

Fig. 11. Harmonic dials for the surface pressure oscillations; $\delta p$ at $3^{\circ} \mathrm{N}, 17^{\circ} \mathrm{N}$ and $32^{\circ} \mathrm{N}$ in the model atmosphere used in this paper. Capital " $I$ " denotes the isothermal model.

difference between the oscillation in E-W model and in case of steps I and II is large at these levels and this also shows that the effects of the zonal wind and its horizontal shear is very large.

This may sound as if in contradiction with Chiu's conclusion (1953) that the free period of the first mode of the westward traveling wave with a zonal wave number of $S=2$ in an imcompressible homogeneous fluid layer or in an autobarotropic atmosphere (hereafter, this mode is called as $S_{2}$ ) is not sensitive to the zonal winds. However, one should notice that, in his model, the mean depth of the fluid layer must change at the same time depending on the speed of the zonal wind, for example, the mean depth of the fluid layer which is assumed $8 \mathrm{~km}$ in case of no zonal wind must increase to $8.88 \mathrm{~km}$ when a zonal wind system of the form $\frac{2}{33} a \omega \sin \varphi$ is assumed. Corresponding to the increase of the depth to $8.88 \mathrm{~km}$, the free period tends to be shorter than that of $8 \mathrm{~km}$ layer. On the other hand, assumed zonal wind system of the form $\frac{2}{33} a \omega \sin \varphi$ tends to increase the free period by a Doppler-effect. Then, the effect of the change of mean depth and the Doppler-effect tend to compensate each other. This is remarkable only for $S_{2}$, in which the effect of Doppler-shift by the zonal wind system happen to be mostly compensated by that of the change in the mean depth. In case of the other modes which are shown in his paper, this compensation is small, and the effect of the zonal wind seems to be large. The above discussion is also applicable to an autobarotropic atmosphere if the mean depth is replaced by the equivalent depth. In case of a forced oscillation, the period is given beforehand, and the equivalent depth must be determined as an eigen value, and it is dependent greatly upon the zonal winds and its horizontal shear. This property agrees well with the results of Ivanovsky and Semenovsky (1971). Thus, Chiu's result does not mean that the effect of the zonal wind on the semidiurnal tide is negligibly small.

The surface pressure oscillations at various latitudes in present model atmospheres are shown in Fig. 11. This figure shows that both the amplitude and the phase are sensitive to the zonal wind system.

It should be remarked that the latitudinally asymmetric distribution of the surface pressure oscillation found in E-W model resembles to the statistically observed pattern in the so-called $D$ season, during which the zonal wind systems are similar to that of the E-W model (Haurwitz and Cowly, 1970, Miyahara, 1972). Though the model used here are simple, the present results suggest that the seasonal variation of the zonal wind system may be one of the most important causes of that of the lunar tide.

\section{Conclusions}

The effects on the semidiurnal lunar tide of the meridional temperature gradient and the associated zonal wind system are discussed by a linear theory with a numerical method. 
It is found that:

1. The effects of the zonal wind and its horizontal shear are considerable. The vertical wave length of the tidal wave is reduced by an equatorsymmetric easterly wind system, but is lengthened by an equator-symmetric westerly wind system, while it is changed a little by an equatorantisymmetric zonal wind system.

The semidiurnal lunar tide has larger amplitudes in a westerly wind system region than in an easterly wind system region. These results are consistent with the result given by Ivanovsky and Semenovsky (1971).

An apparently contradicted conclusion given by Chiu (1953) for this problem is compatible with these results. In his model the Doppler-effect by the zonal wind system happens to be compensated by the effect of the change in the meandepth or the equivalent depth associated with the zonal winds.

2. The effects of the vertical shear of the zonal winds are also remarkable. This is consistent with the results given by Sawada (1966). The semidiurnal lunar tide has larger amplitudes in a positive wind shear than in a negative one. The vertical wave length is changed slightly by equatorasymmetric wind shears.

These results are consistent with the results given by Kusuda and Sawada (1974).

3. The effects of the meridional temperature gradient alone on the surface oscillation is less important than the above mentioned effects, and this is consistent with the results given by Haurwitz (1957) and Siebert (1957). These effects, however, are important in the upper atmosphere. The amplitude is larger in the hemisphere which has low mean temperature than in the hemisphere which has high mean temperature in case of the present atmospheric model.

4. The seasonal variation of the zonal wind system may be one of the most important causes of that of the lunar tide.

\section{Acknowledgements}

The author wishes to express his thanks to Prof. R. Sawada and Prof. M. Uryu, Kyushu University for their critical readings of the manuscript and valuable advices and comments.

Thanks are due to Prof. T. Matsuno, Tokyo University, for his suggestions and discussions.

Thanks are also due to Miss. Y. Sato for her drawing figures.
The computations were performed by the use of FACOM 230-60 computer at Kyushu University.

\section{References}

Chiu, W. C., 1953: On the oscillations of the atmosphere. Arch. Met. Geoph. Biokl. A5, 280-303.

Haurwitz, B., 1957: Atmospheric oscillations and meridional temperature gradient. Beitr. Phys. Atmosph. 30, 47-54.

, and Cowly, A. B., 1970: The lunar barometric tide, its global distribution and annual variation. Pure and Applied Geophysics. 75, 1-29.

Ivanovsky, A. I. and Semenovsky, Yu. v., 1971: Teoriia polusutochngo priliva s uchetom vliianiia zonal'nogo vetra. Akademiia Nank SSSR, Izvestiia. Fizika Atmosfery i Okena. 7(3), 246-254.

Jones, W. L., 1967: Propagation of internal gravity waves in fluids with shear flow and rotation. $J$. Fluid Mech. 30, 439-448.

Kusuda, M. and Sawada, R., 1974: Combined effects of zonal wind and the vertical temperature profile on the atmospheric lunar tide. (in preparation)

Lindzen, R. S., 1970: Internal gravity waves in atmosphers with realistic dissipation and temperature Part I. Mathematical development and propagation of waves into the thermosphere. Geophy. Fluid Dynamics. 1, 303-355.

, and Hong, S., 1974: Effects of mean winds and horizontal temperature gradients on solar and lunar semidiurnal tides in the atmosphere. J. Atmos. Sci. 31, 1421-1446.

, and Kuo, H. L., 1969: A reliable method for the numerical integration of a large class of ordinary and partial differential equations. Mon. Wea. Rev. 97, 732-734.

Miyahara, S., 1972: The earth tide correction for the surface barometric lunar tide. J. Meteor. Soc. Japan. 50, 342-345.

Sawada, R., 1956: The atmospheric lunar tides and the temperature profile in the upper atmosphere. Geophys. Mag. 27, 213-236.

- 1966: The effects of zonal winds on the atmospheric lunar tide. Arch. Met. Geoph. Biokl. A15, 129-167.

Siebert, M. 1957: Tidal oscillations in an atmosphere with meridional temperature gradient. Scientfic Rep. No. 3, 16, Dept. Met. Ocean., New York Univ.

Stokke, E. B., 1969: The semidiurnal oscillation in a thermal-geostrophic atmosphere. J. Atmos. Sci. 26, 335-351.

Wilkes, M. V., 1963: Oscillations of the earth's atmosphere with allowance for the variation of temperature with latitude. Proc. Roy. Soc. London. A158, 44-56. 


\section{APPENDIX I}

List of symbols

$a:$ radious of the earth

$f:=\sigma / 2 \omega$, nondimensional angular frequency

$f^{\prime}:=\sigma^{\prime} / 2 \omega^{\prime}$, nondimensional angular frequency modified by zonal wind

$g$ : acceleration of gravity

$H$ : scale height

$P$ : undisturbed pressure

$\delta p$ : perturbation of pressure

$Q:=\frac{\delta p}{\rho_{0}}+\Omega$

$s:$ zonal wave number

$T$ : temperature of basic state

$u$ : perturbation of southward wind component

$v:$ perturbation of eastward wind component

$V$ : basic zonal wind

$w$ : perturbation of upward wind component

$z:$ height

$\gamma:$ ratio of specific heats for air

$\varepsilon$ : inclination of isentropic surface

$\theta:$ potential temperature

$\kappa:=\frac{\gamma-1}{\gamma}$

$\sigma:$ angular frequency of the tide

$\sigma^{\prime}:=\sigma+\frac{s V}{a \sin \varphi}$, Doppler-shifted angular frequency

$\mu:=\cos \varphi$

$\varphi$ : colatitude

$\rho_{0}$ : undisturbed density

$\delta \rho$ : perturbation of density

$\Omega$ : tide-generating potential;

$$
-2.61855 \times 10^{4}\left(1+\frac{z}{a}\right)^{2} \sin ^{2} \varphi \mathrm{cm}^{2} / \mathrm{sec}^{2}
$$

$\omega$ : angular velocity of the earth's rotation

$\chi:$ divergence

$\omega^{\prime}:=\omega+\frac{V}{a \sin \varphi}$, absolute angular velocity of the zonal wind

\section{APPENDIX II}

Equation (2.8) can be obtained by the following two steps. First, equation (2.2) through (2.7) are combined on an isentropic surface into the single equation for $Q$ which is $\frac{\delta p}{\rho_{0}}+\Omega$, as done by Sawada (1966), and secondly, the resulting single equation is rewritten as that on a horizontal surface.

From equation (2.1), the hydrostatic relationship and the ideal gas equation, we obtain the inclina- tion $\varepsilon$ of any undisturbed isentropic surface as follows:

$$
\begin{aligned}
& \tan \varepsilon=-\frac{H}{g} \cdot \\
& \frac{\left(2 \omega \mu+\frac{\cot \varphi}{a} V\right)\left\{\frac{\partial V}{\partial z}-\frac{V}{H}\left(\kappa+\frac{\partial H}{\partial z}\right)\right\}+\frac{\cot \varphi}{a} V \frac{\partial V}{\partial z}}{\kappa+\frac{\partial H}{\partial z}}
\end{aligned}
$$

we introduce the following differential operator along the isentropic surface:

$$
\frac{\partial}{\partial \varphi_{\theta}}=\frac{\partial}{\partial \varphi}+a \tan \varepsilon \cdot \frac{\partial}{\partial z},
$$

and the vertical velocity $w_{r}$ relative to the undisturbed isentropic surface:

$$
w_{r}=w-u \tan \varepsilon
$$

Using (A.1), (A.2) and (A.3), we get the following equations from equations (2.4), (2.5) and (2.6),

$$
\begin{gathered}
\chi=-\frac{i \sigma^{\prime} \frac{\partial Q}{\partial z}+2 \omega^{\prime} \mu \frac{\partial V}{\partial z} u}{g r\left(\kappa+\frac{\partial H}{\partial z}\right)} \\
w_{r}=\frac{i \sigma^{\prime}}{g}\left[1+\frac{H}{\kappa+\frac{\partial H}{\partial z}} \frac{\partial}{\partial z}\right] Q-\frac{i \sigma^{\prime}}{g} \Omega,
\end{gathered}
$$

and the equations (2.2) and (2.3) are written along the isentropic surface as follows:

$$
\begin{gathered}
i \sigma^{\prime} u-2 \omega^{\prime} \mu\left(v-\frac{i}{\sigma^{\prime}} w_{r} \frac{\partial V}{\partial z}\right)=-\frac{1}{a} \frac{\partial Q}{\partial \varphi_{\theta}} \\
\begin{aligned}
i \sigma^{\prime}\left(v-\frac{i}{\sigma^{\prime}} w_{r} \frac{\partial V}{\partial z}\right) & +\left(2 \omega \mu+\frac{1}{a} \frac{\partial V}{\partial \varphi_{\theta}}+\frac{\cot \varphi}{a} V\right) u \\
& =-\frac{i s}{a \sin \varphi} Q
\end{aligned}
\end{gathered}
$$

Solving (A.6) and (A.7), and substituting (A.5) into the result, we obtain

$$
\begin{aligned}
& u=\frac{i \sigma^{\prime}}{4 a \omega^{\prime 2} L}\left[\frac{\partial}{\partial \varphi_{\theta}}+\frac{s}{f^{\prime}} \cot \varphi\right] Q \\
& v=\frac{-\sigma^{\prime}}{4 a \omega^{\prime 2} L}\left[\left(\frac{\mu}{f^{\prime}}+\frac{1}{a \sigma^{\prime}} \frac{\partial V}{\partial \varphi_{\theta}}-\frac{\cot \varphi}{a \sigma^{\prime}} V\right) \frac{\partial}{\partial \varphi_{\theta}}+\frac{s}{\sin \varphi}\right] \\
& -\frac{1}{g} \frac{\partial V}{\partial z}\left[1-\frac{H}{\kappa+\frac{\partial H}{\partial z}} \frac{\partial}{\partial z}\right] Q+\frac{1}{g} \frac{\partial V}{\partial z} \Omega
\end{aligned}
$$


where

$$
L=f^{\prime 2}-\mu^{2}-\frac{\mu}{2 a \omega^{\prime}} \frac{\partial V}{\partial \varphi_{\theta}}+\frac{\mu}{2 a \omega^{\prime}} \cot \varphi V .
$$

The divergence defined as (2.7) is written as follows by using (A.2) and (A.3),

$$
\chi=\frac{1}{a \sin \varphi}\left(\frac{\partial u \sin \varphi}{\partial \varphi_{\theta}}+i s v\right)+\frac{\partial w_{r}}{\partial z}+u \frac{\partial \tan \varepsilon}{\partial z} .
$$

Substituting equations (A.4), (A.5), (A.8) and (A.9) into (A.11), we get the following single equation for $Q$.

$$
\begin{aligned}
& H \frac{\partial^{2} Q}{\partial z^{2}}-\left\{1+\frac{H \frac{\partial^{2} H}{\partial z^{2}}}{\kappa+\frac{\partial H}{\partial z}}-\frac{1}{\sigma^{\prime}} \frac{\partial \sigma^{\prime}}{\partial z} H\right\} \frac{\partial Q}{\partial z} \\
& -g\left(\kappa+\frac{\partial H}{\partial z}\right)\left\{\frac{\partial \tan \varepsilon}{\partial z}+\frac{2 \omega^{\prime} \mu \frac{\partial V}{\partial z}}{\gamma g\left(\kappa+\frac{\partial H}{\partial z}\right)}\right\} . \\
& \frac{1}{4 a \omega^{\prime 2} L}\left[\frac{\partial}{\partial \varphi_{\theta}}+\frac{s}{f^{\prime}} \cot \varphi\right] Q \\
& +\frac{s\left(\kappa+\frac{\partial H}{\partial z}\right)}{a \sigma^{\prime} \sin \varphi} \frac{\partial V}{\partial z}\left\{1-\frac{H}{\kappa+\frac{\partial H}{\partial z}} \frac{\partial}{\partial z}\right\} Q \\
& -\frac{\kappa+\frac{\partial H}{\partial z}}{\sigma^{\prime}} \frac{\partial \sigma^{\prime}}{\partial z} Q-\frac{g\left(\kappa+\frac{\partial H}{\partial z}\right)}{4 a^{2} \sigma^{\prime}} . \\
& {\left[\frac{1}{\sin \varphi} \frac{\partial}{\partial \varphi_{\theta}}\left\{\frac{\sigma^{\prime} \sin \varphi}{L \omega^{\prime 2}}\left(\frac{\partial}{\partial \varphi_{\theta}}+\frac{s}{f^{\prime}} \cot \varphi\right)\right\} Q\right.} \\
& -\frac{\sigma^{\prime} s}{\omega^{\prime 2} L \sin \varphi}\left\{\left(\frac{\mu}{f^{\prime}}+\frac{1}{a \sigma^{\prime}} \frac{\partial V}{\partial \varphi_{\theta}}-\frac{\cot \varphi}{a \sigma^{\prime}} V\right) \frac{\partial}{\partial \varphi_{\theta}}\right. \\
& \left.\left.+\frac{s}{\sin \varphi}\right\} Q\right]=-\frac{\kappa+\frac{\partial H}{\partial z}}{\sigma^{\prime}} \frac{\partial\left(\sigma^{\prime} \Omega\right)}{\partial z} \\
& +\frac{s\left(\kappa+\frac{\partial H}{\partial z}\right)}{a \sigma^{\prime} \sin \varphi} \frac{\partial V}{\partial z} \Omega \text {. }
\end{aligned}
$$

No terms are neglected in the process of deriving this equation.

For numerical integration, it is more convenient to write this equation on a horizontal surface rather than on an isentropic surface and to use the $\mu(=\cos \varphi)$ in place of $\varphi$ as a horizontal coordinate. (A.2) may be rewritten as follows:

$$
\frac{\partial}{\partial \varphi_{\theta}}=-\sqrt{1-\mu^{2}} \frac{\partial}{\partial \mu}+a \tan \varepsilon \cdot \frac{\partial}{\partial z} .
$$

Substituting (A.13) into (A.12), we get

$$
\begin{aligned}
A \frac{\partial^{2} Q}{\partial z^{2}} & +B \frac{\partial Q}{\partial z}+C \frac{\partial Q}{\partial \mu}+D \frac{\partial}{\partial \mu}\left[E \frac{\partial Q}{\partial \mu}\right] \\
& +F \frac{\partial}{\partial \mu}[G Q]+I \frac{\partial}{\partial \mu}\left[J \frac{\partial Q}{\partial z}\right] \\
& +K \frac{\partial}{\partial z}\left[M \frac{\partial Q}{\partial \mu}\right]+N \frac{\partial}{\partial z}\left[O \frac{\partial Q}{\partial z}\right] \\
& +R \frac{\partial}{\partial z}[S Q]+U Q=W,
\end{aligned}
$$

where

$$
\begin{aligned}
A= & H, \\
B= & -\left(1+\frac{H \frac{\partial^{2} H}{\partial z^{2}}}{\kappa+\frac{\partial H}{\partial z}}-\frac{1}{\sigma^{\prime}} \frac{\partial \sigma^{\prime}}{\partial z} H\right) \\
& -\frac{g\left(\kappa+\frac{\partial H}{\partial z}\right)\left\{\frac{\partial \tan \varepsilon}{\partial z}+\frac{2 \omega^{\prime} \mu \frac{\partial V}{\partial z}}{\gamma g\left(\kappa+\frac{\partial H}{\partial z}\right)}\right\} \tan \varepsilon}{4 \omega^{\prime 2} L} \\
& -\frac{s H}{a \sigma^{\prime} \sqrt{1-\mu^{2}}} \frac{\partial V}{\partial z}+\frac{g\left(\kappa+\frac{\partial H}{\partial z}\right) s}{4 a \omega^{\prime 2} L \sqrt{1-\mu^{2}}} \\
& \left(\frac{\mu}{f^{\prime}}+\frac{1}{a \sigma^{\prime}} \frac{\partial V}{\partial \varphi_{\theta}}-\frac{\cot \varphi}{a \sigma^{\prime}} V\right) \tan \varepsilon,
\end{aligned}
$$$$
C=g\left(\kappa+\frac{\partial H}{\partial z}\right)\left\{\frac{\partial \tan \varepsilon}{\partial z}+\frac{2 \omega^{\prime} \mu \frac{\partial V}{\partial z}}{r g\left(\kappa+\frac{\partial H}{\partial z}\right)}\right\} \cdot \frac{\sqrt{1-\mu^{2}}}{4 a \omega^{\prime 2} L}
$$$$
-\frac{g\left(\kappa+\frac{\partial H}{\partial z}\right) s}{4 a^{2} \omega^{\prime 2} L}\left(\frac{\mu}{f^{\prime}}+\frac{1}{a \sigma^{\prime}} \frac{\partial V}{\partial \varphi_{\theta}}-\frac{\cot \varphi}{a \sigma^{\prime}} V\right),
$$$$
D=-\frac{g\left(\kappa+\frac{\partial H}{\partial z}\right)}{4 a^{2} \sigma^{\prime}}, \quad E=\frac{\sigma^{\prime}\left(1-\mu^{2}\right)}{\omega^{\prime 2} L},
$$$$
F=\frac{g_{S}\left(\kappa+\frac{\partial H}{\partial z}\right)}{4 a^{2} \sigma^{\prime}}, \quad G=\frac{\sigma^{\prime} \mu}{\omega^{\prime 2} L f^{\prime}},
$$$$
I=\frac{g\left(\kappa+\frac{\partial H}{\partial z}\right)}{4 a \sigma^{\prime}}, \quad J=\frac{\sigma^{\prime} \sqrt{1-\mu^{2}} \tan \varepsilon}{\omega^{\prime 2} L},
$$$$
K=\frac{g\left(\kappa+\frac{\partial H}{\partial z}\right)}{4 a \sigma^{\prime}} \sqrt{1-\mu^{2}} \tan \varepsilon, \quad M=\frac{\sigma^{\prime}}{\omega^{\prime 2} L},
$$

$N=-\frac{g\left(\kappa+\frac{\partial H}{\partial z}\right)}{4 \sigma^{\prime}} \tan \varepsilon, \quad O=\frac{\sigma^{\prime} \tan \varepsilon}{\omega^{\prime 2} L}$, 


$$
\begin{aligned}
R= & -\frac{g s\left(\kappa+\frac{\partial H}{\partial z}\right) \mu \tan \varepsilon}{4 a \sigma^{\prime} \sqrt{1-\mu^{2}}}, \quad S=\frac{\sigma^{\prime}}{\omega^{\prime 2} f^{\prime} L}, \quad W=-\frac{\kappa+\frac{\partial H}{\partial z}}{\sigma^{\prime}} \frac{\partial\left(\sigma^{\prime} \Omega\right)}{\partial z}+\frac{s\left(\kappa+\frac{\partial H}{\partial z}\right)}{a \sigma^{\prime} \sqrt{1-\mu^{2}}} \frac{\partial V}{\partial z} \Omega . \\
U=- & g\left(\kappa+\frac{\partial H}{\partial z}\right)\left\{\frac{\partial \tan \varepsilon}{\partial z}+\frac{2 \omega^{\prime} \mu \frac{\partial V}{\partial z}}{\gamma g\left(\kappa+\frac{\partial H}{\partial z}\right)}\right\} . \\
& \frac{s}{4 a \omega^{\prime 2} f^{\prime} L} \frac{\mu}{\sqrt{1-\mu^{2}}}+\frac{s\left(\kappa+\frac{\partial H}{\partial z}\right)}{a \sigma^{\prime} \sqrt{1-\mu^{2}}} \frac{\partial V}{\partial z} \\
+ & \frac{g\left(\kappa+\frac{\partial H}{\partial z}\right)}{4 a^{2} \omega^{\prime 2}} \cdot \frac{s^{2}}{L\left(1-\mu^{2}\right)}-\frac{\left(\kappa+\frac{\partial H}{\partial z}\right)}{\sigma^{\prime}} \frac{\partial \sigma^{\prime}}{\partial z},
\end{aligned}
$$

\title{
半日大気太陰潮に対する南北方向の温度傾度と帯状風の影響
}

\author{
宮原 三 郎 \\ 九州大学理学部物理学教室
}

南北方向の温度傾向と，それに伴ら帯状風が半日大気太陰潮に及汸す影響を線型論に基づき，数値的に調べた.

帯状風及びその水平シアーの影響が非常に大きい事が明らかになった。

また，帯状風の垂直シアーもまた大きな影響を与える。これらは，振動の南北分布や，垂直波長を変化させる。た とえば，偏西風中では，偏東風中よりも振幅が大きくなる傾向をもっているまをた，南北対称な偏西風は，垂直波長 を長くし，対称な偏東風は短くする。

南北方向の水平温度傾度自身は，地表面付近以外の振動に対しては，かなり大きな影響をもつ.

帯状風の季節変化が，太陰半日潮の季節変動の重要な原因の一つである可能性が高い. 